\title{
Influence of equal-channel angular extrusion on impact toughness of aluminum and brass at room and low temperatures
}

\author{
Jyhwen Wang ${ }^{1,2}$, Huanlin Zhu' ${ }^{2}$ K Vadiraja Sudhakar ${ }^{3^{*}}$ and Angie Hill Price
}

\begin{abstract}
Background: Equal-channel angular extrusion is a severe plastic deformation process that can be used for grain refinement to improve material properties of bulk metals. In this paper, the effect of equal-channel angular extrusion on the impact toughness of aluminum 1100 and brass C26000 was investigated.

Methods: Brass and aluminum materials were extruded in two and four passes using two equal-channel angular extrusion processing routes. Specimens were tested for hardness and Charpy impact toughness. Microstructure and fractography were examined.

Results: The results showed the hardness remained almost constant after two passes for both brass and aluminum. Impact energy of brass after two passes decreased due to increase in dislocation density whereas for aluminum it remained almost constant after four passes due to the formation of ultrafine grains in addition to deformation/ dislocation structures. Impact energies of specimens tested at room temperature and low temperature $\left(-70^{\circ} \mathrm{C}\right)$ were almost the same due to their face-centered crystal structure. It was also found that the impact toughness of a specimen with a non-distorted notch surface is higher than that of a specimen with a distorted notch surface.

Conclusions: It is evident from the present study that the number of passes determines the extent of ultrafine grain structure that is known to increase impact toughness of equal-channel angular extrusion processed materials. All of these observed characteristics can influence material and process selections in practical design applications.
\end{abstract}

Keywords: Equal-channel angular extrusion; Hardness; Impact toughness; Microstructure

\section{Background}

Equal-channel angular extrusion (ECAE), twist extrusion, high pressure torsion, and friction stir processing are all severe plastic deformation (SPD) processes that can result in ultrafine grain (UFG) microstructures in metals. As UFG materials are known to exhibit enhanced mechanical properties, SPD processes have been extensively studied (Valiev and Langdon 2006). In ECAE, the workpiece/billet is pressed through a die with intersecting channels having the same cross section. The material is subjected to simple shear at the intersecting plane of the two channels. As the billet can be extruded repeatedly in successive passes, ECAE has the advantage of producing large cumulative strain without changing the cross section of the workpiece

\footnotetext{
* Correspondence: kvsudhakar@metch.edu

${ }^{3}$ Department of Metallurgical and Materials Engineering, Montana Tech of the University of Montana, Butte, MT 59701, USA

Full list of author information is available at the end of the article
}

(Rebhi et al. 2009). The workpiece possesses fine grains with enhanced properties that can have various design applications.

For multiple-pass ECAE, there are different routes that can be used to introduce different slip systems. A commonly used designation of the processing routes was presented in Rebhi et al. (2009) and Iwahashi et al. (1997a). In route $\mathrm{A}$, the workpiece is pressed without rotation between passes. In route $B_{A}$, the workpiece is rotated $90^{\circ}$ in alternate directions, clockwise then counterclockwise or vice versa, between consecutive passes. In route $B_{C}$, the workpiece is rotated $90^{\circ}$ in the same direction, either clockwise or counterclockwise, between consecutive passes. In route $\mathrm{C}$, the workpiece is rotated $180^{\circ}$ between passes. With different processing routes, different microstructures can be produced from the same initial workpiece. Research has shown that the large equiaxed grains in a billet can be significantly distorted during 
ECAE. The influence of various ECAE routes on the texture and plastic anisotropy of the material has been investigated (Iwahashi et al. 1997a; Xiao et al. 2012; Li et al. 2004; Stolyarov et al. 2001; Xu et al. 2008).

It is known that the strength of a polycrystalline material is related to the grain size. As the yield strength increases with a decreased grain size, ultrafine grain materials produced from ECAE have gained significant attention. While high strength materials resulting from straining generally exhibit low ductility, ECAE processing typically leads to a reduction in the ductility which is less than that resulting from conventional bulk forming processes such as rolling, drawing, and extrusion. It is also reported that most of the materials processed by ECAE have a relatively low ductility, but they usually demonstrate significantly higher strength than their coarser-grained counterparts (Valiev and Langdon 2006). Physical and mechanical properties, such as hardness, yield strength, and the strain hardening exponent, have been investigated (Reihanian et al. 2008; Firstov et al. 2003). Other attractive characteristics such as superelasticity, wear resistance, and enhanced fatigue behavior of UFG materials have also been observed ( $\mathrm{Li}$ and Cheng 2010; Crone et al. 2001; Höppel et al. 2006).

Impact toughness, while not a direct measure of the fracture toughness, is commonly used to evaluate the relative fracture behavior of engineering materials. Experimental results regarding the effect of ECAE on the impact toughness are very limited. Although it was reported that the impact toughness of two-phase $\mathrm{Zn}-40 \mathrm{Al}$ alloy can be improved through ECAE (Purcek et al. 2008), it is noticed that the tested material also exhibited strain softening that is not common in cold forming of metals. It has also been reported that when the grain size is below a critical value, the dominating deformation and fracture mechanisms can change ( $\mathrm{Li}$ and Ebrahimi 2005). The impact toughness of nanostructured Ti processed by SPD was enhanced with decreasing testing temperature. The phenomenon is attributed to the small fracture dimples at lower temperatures (Stolyarov et al. 2006). However, it is not known if any other UFG materials have a similar behavior. The present study assesses the hardness and the impact toughness of aluminum 1100 and brass C26000 before and after ECAE processing. Charpy impact tests of specimens prepared from two ECAE routes were conducted at two different testing temperatures. The fractographs were examined, and the fracture morphology of the specimen was discussed.

\section{Methods}

\section{Sample preparation}

Aluminum 1100 and 70-30 brass (C26000) materials were used in the experimental investigation. The materials were extruded through an ECAE die with a $90^{\circ}$ die angle at room temperature. For the aluminum samples, routes $\mathrm{B}_{\mathrm{C}}$ (four passes) and $\mathrm{C}$ (two passes) were used, while the brass samples were processed using route $C$ (two passes). Note that both routes $\mathrm{B}_{\mathrm{C}}$ and $\mathrm{C}$ can result in redundant strain path as the slip is cancelled and strain is restored in four passes and two passes, respectively. The slip systems viewed on the $x, y$, and $z$ planes (Valiev and Langdon 2006) are shown in Figure 1. The specimens were prepared from two configurations as shown in Figure 2a,b. The length direction of the impact specimen was parallel to the extrusion direction. The middle sections were used for hardness measurement and microstructure evaluation of the materials before and after ECAE. The notch on the specimen was always on the narrower surface. Therefore, a specimen prepared from a billet shown in Figure 2a had the notch on the $z$ plane (top surface), while that in Figure $2 \mathrm{~b}$ had the notch on the $y$ plane (front surface). All specimens were cut using electrical discharge machining (EDM) process. The dimension of each specimen was $55 \mathrm{~mm}$ long by $10 \mathrm{~mm}$ thick by $5 \mathrm{~mm}$ wide. The notch angle was $45^{\circ}$; the depth of the notch was $2 \mathrm{~mm}$; and the radius at the root was $0.25 \mathrm{~mm}$. Figure 3 shows the specification of the subsized impact specimen according to ASTM E23. Each notch was inspected with an optical microscope as shown in Figure 4. The designation of the specimens is summarized in Table 1.

\section{Microstructural evaluation, hardness measurement, and impact toughness test}

Aluminum and brass samples were cut from the middle sections of the billets; specimens for metallographic observation were prepared using standard polishing techniques and etched with Keller's reagent $\left(2.5 \mathrm{~mL} \mathrm{HNO}_{3}\right.$, $1.5 \mathrm{~mL} \mathrm{HCl}, 1.0 \mathrm{~mL} \mathrm{HF}$, and $95 \mathrm{ml}$ water) for aluminum, and ammonium persulfate solution ( $10 \%$ in water) for

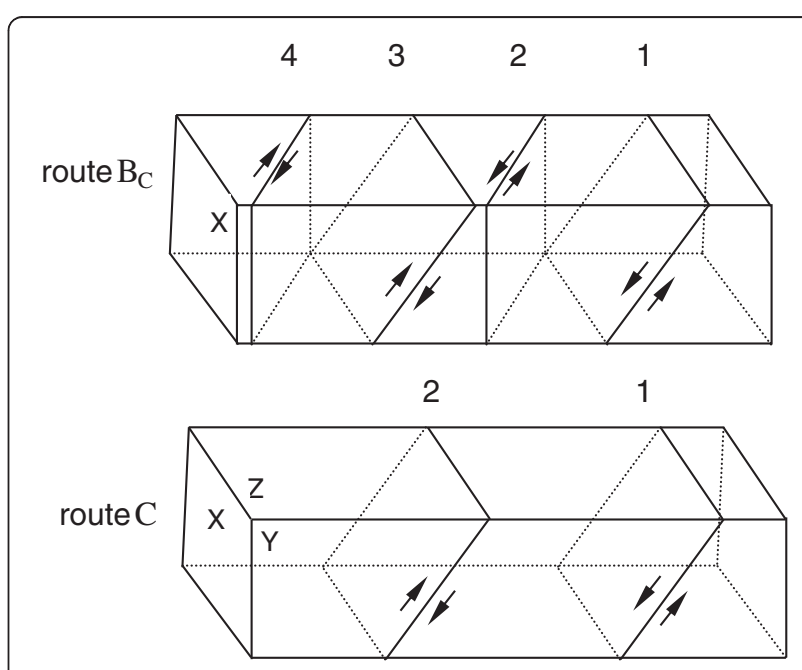

Figure 1 The slip systems viewed on the $x, y$, and $z$ planes for routes $\mathbf{B}_{\mathbf{C}}$ and $\mathbf{C}$. Modified from Valiev and Langdon (2006). 


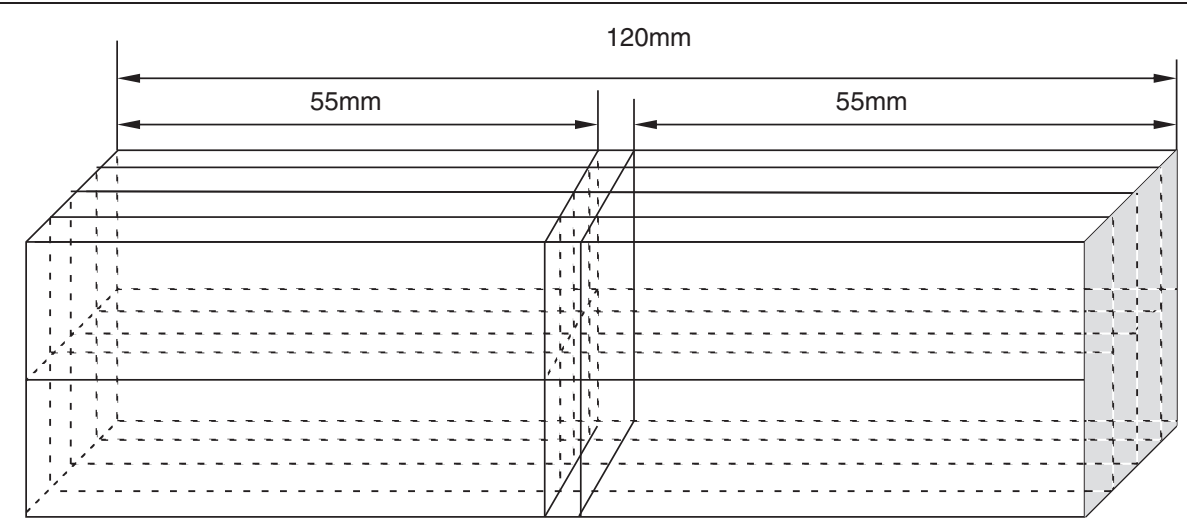

(a)

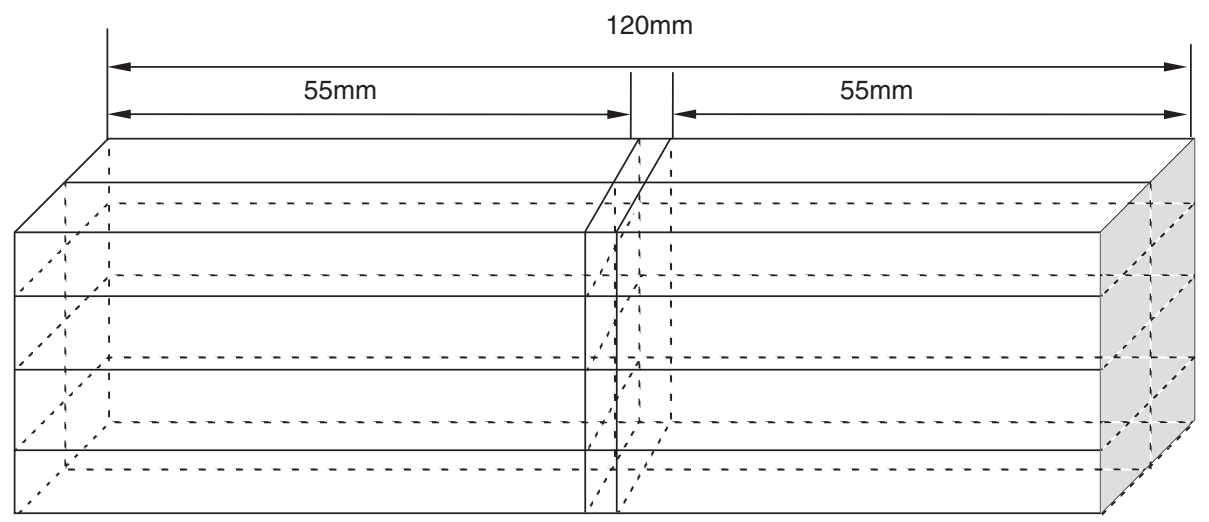

(b)

Figure 2 Specimens prepared from two configurations. Specimens with (a) notch on top surface (z plane) and (b) notch on side surface (y plane).

brass. An optical microscope Leica DM750P (Leica Microsystems, Wetzlar, Germany) was used to examine the microstructures of the materials before and after ECAE.

Hardness tests were performed on the samples, also from the center of the billets, using a Buehler Macromet 3 hardness tester (Buehler, Lake Bluff, USA). The hardness test was repeated three times for each material parameter shown in Table 1. The hardness tests were performed on both the top ( $z$ plane) and side ( $y$ plane) of

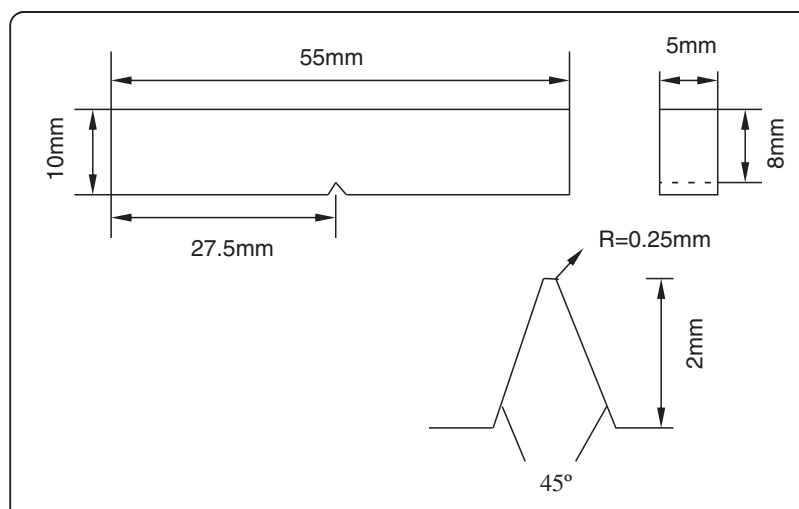

Figure 3 Subsized V-notch specimen for Charpy impact test. the billets. For aluminum, HR15T was used, while HRA was used for brass.

Charpy impact tests were conducted on the notched specimen using a Tinius Olsen Model 104 Impact Tester (Tinius Olsen, Inc., Horsham, USA). The specimens were

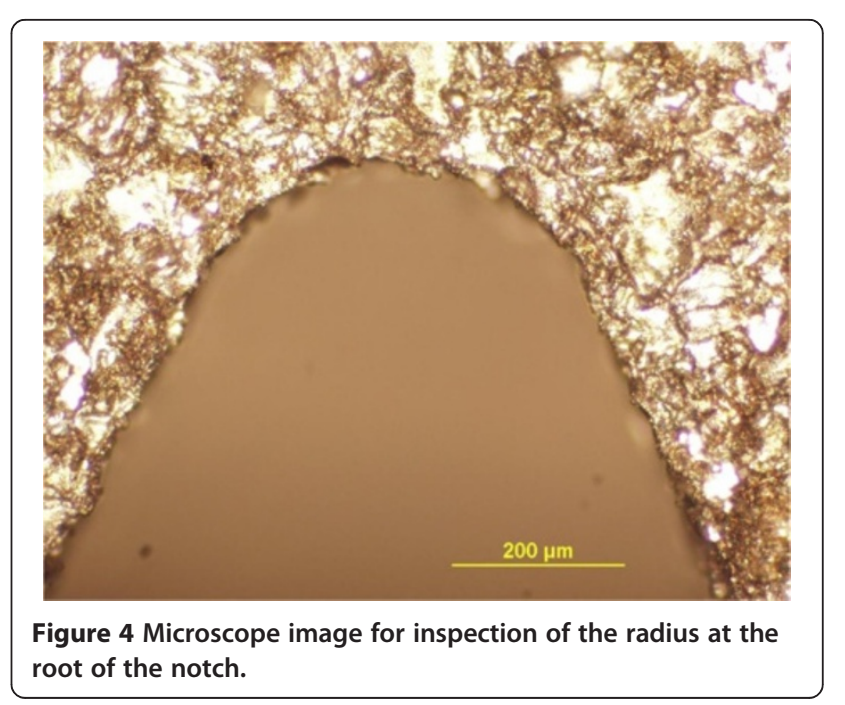


Table 1 Specimen designation

\begin{tabular}{llll}
\hline & Material & Process routes & Notch surface \\
\hline A1 & Aluminum 1100 & As received & z plane (top) \\
A2 & Aluminum 1100 & C, two passes & z plane (top) \\
A3 & Aluminum 1100 & C, two passes & y plane (side) \\
A4 & Aluminum 1100 & B, four passes & z plane (top) \\
B1 & Brass C26000 & As received & z plane (top) \\
B2 & Brass C26000 & C, two passes & z plane (top) \\
B3 & Brass C26000 & C, two passes & y plane (side) \\
\hline
\end{tabular}

tested at room temperature $\left(24.7^{\circ} \mathrm{C}\right)$ and low temperature $\left(-70^{\circ} \mathrm{C}\right)$. For low temperature testing, the specimens were submerged in methanol in a Kinetics Multi Cool MC480A1 chiller for a minimum of $5 \mathrm{~min}$. In each test, the time to extract and place the specimen in position and strike the specimen was less than $5 \mathrm{~s}$. SEM examination of the fractured impact specimens was carried out using HITACHI-4500 (Hitachi High Technologies America, Inc., Pleasanton, USA) and LEO $1430 \mathrm{VP}$ scanning electron microscopes.

\section{Results and discussion}

\section{Microstructure evolution and its influence on} impact toughness

The aluminum 1100 contains approximately $1.2 \%$ of impurities consisting of mainly iron, silicon, copper, and zinc. These secondary elements form precipitates in the aluminum matrix that are evident from optical microscopic studies as shown in Figure 5. These precipitates tend to get segregated at the grain boundaries as they move towards the region of high energy/crystal defects. Undeformed samples contain a low dislocation density. After ECAE, the microstructure of deformed material shows the presence of almost parallel and elongated grains. Many of the dislocations are pinned by the precipitates. Dislocations also segregate inside the grains (subgrains) that are very fine in size with many dislocation walls. The relatively uniform and equiaxed grains in addition to randomly distributed precipitates in the specimens prior to processing (as-received condition) become elongated and aligned along the direction of shearing/extrusion after processing. The extent of the shear deformation is observed to increase with increasing number of passes (Sivakumar and Ortiz 2004; Langdon et al. 2000). The micrographs of aluminum are shown in Figure 5. Figure 5a corresponds to A1 specimen showing the distribution of precipitates in aluminum alloys. Figure 5b (from A2 specimen) demonstrates more segregated/aligned precipitates after ECAE processing.

Figure 6 shows the microstructure of brass specimens. The micrograph of the B1 specimen in Figure 6a depicts a typical microstructure of an alpha brass with zinc content being less than $30 \mathrm{wt. \%}$. Brass samples prior to ECAE processing show equiaxed and uniform grains, as demonstrated in Figure 6 .

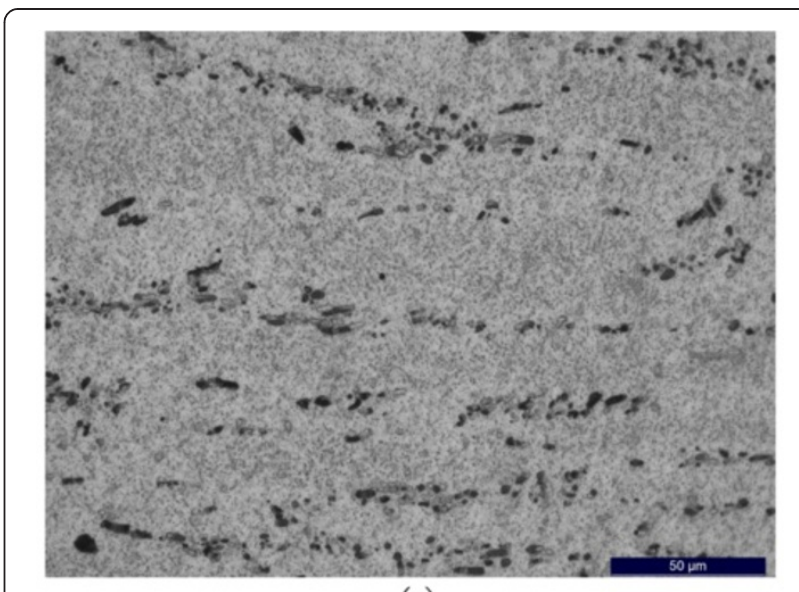

(a)

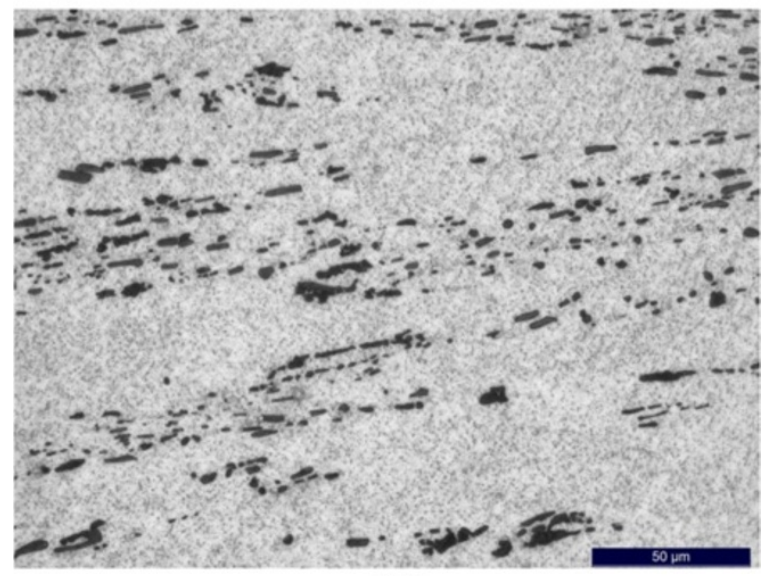

(b)

Figure $\mathbf{5}$ The micrographs of aluminum. The micrographs of aluminum (a) before and (b) after ECAE processing.

Figure $6 \mathrm{~b}$ demonstrates a microstructure with highly ruptured fine grains (dislocation/deformation structures) after ECAE processing. This microstructure is equivalent to a plastically deformed microstructure of brass (B2). The ECAE process involves very large plastic strains and is well known for its ability to refine the grain size of a polycrystalline metal to very fine size scales, depending on the number of passes and the nature/type of material involved. As a result of the ECAE processing, oriented finer grains can be observed in the extruded direction. The grains are elongated (in the direction of extrusion) and there is an evidence of grain refinement (ultrafine grains) as shown in Figure 6b.

It is clear from the micrographs that microstructural evolution leading to fully ultrafine grains (UFG, grain size less than $1 \mu \mathrm{m}$ ) typical of the ECAE process was not achieved after a maximum of two passes in brass. After one and two passes, dislocation cell structure with low angle grain boundaries was formed leading to increase in microstrain (dislocation density) and is evident from impact energy values (presented in Figure 7). Microstructure after 


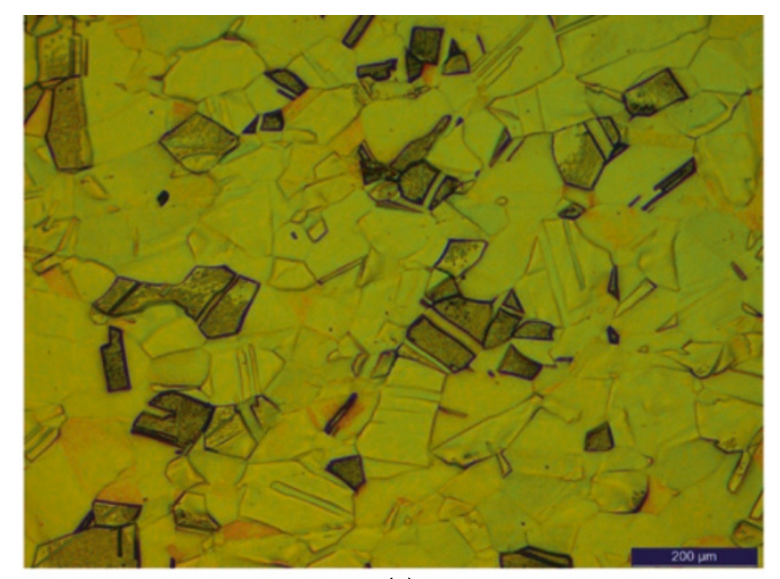

(a)

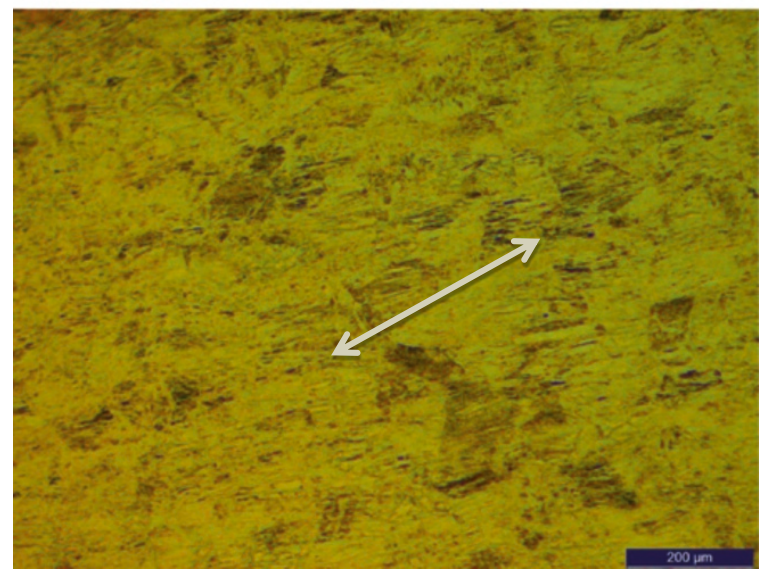

(b)

Figure 6 The microstructure of brass specimens. The optical micrographs of brass specimen B1 (a) before and (b) after ECAE with the arrow indicating the extrusion direction.
ECAE processing with two passes has a predominant deformed structure, due to increase in dislocation density, as demonstrated in Figure 6 (Georgy et al. 2004; Iwahashi et al. 1997b).

ECAE-processed aluminum with severe plastic deformation would demonstrate mostly equiaxed grains and well-defined, sharp grain boundaries that are absent in our present investigation. It has been reported that large grains in UFG materials contain dislocations while grains smaller than a certain size are dislocation free (Valiev et al. 2000; Zhu et al. 2003). Based on the impact energy results (presented in Figure 8), aluminum material used in the present investigation requires more than four passes (to have severe enough plastic deformation) to achieve completely dislocation-free UFG structures.

\section{Hardness}

The hardness test results are shown in Figure 9a,b for aluminum and brass, respectively. From Figure 9a, it can be observed that prior to ECAE (A1), the hardness of aluminum was around $50 \mathrm{HR} 15 \mathrm{~T}$. After ECAE processing (A2, A3, and A4), the hardness of the aluminum material was increased to around $82 \mathrm{HR} 15 \mathrm{~T}$, regardless the route in which the material was processed. The effect of work-hardening was evident. From Figure 9b, a similar trend can be observed for brass. The hardness of the as-received brass was about 34 HRA, and the hardness of the ECAE process samples was around 55 HRA. Again, the material was work-hardened due to ECAE processing. This is attributed to the predominant deformation/ dislocation structures with low angle grain boundaries. The dislocation density typically determines the hardness/ strength of a material in dislocation structures. Intersections between dislocations in these high dislocation

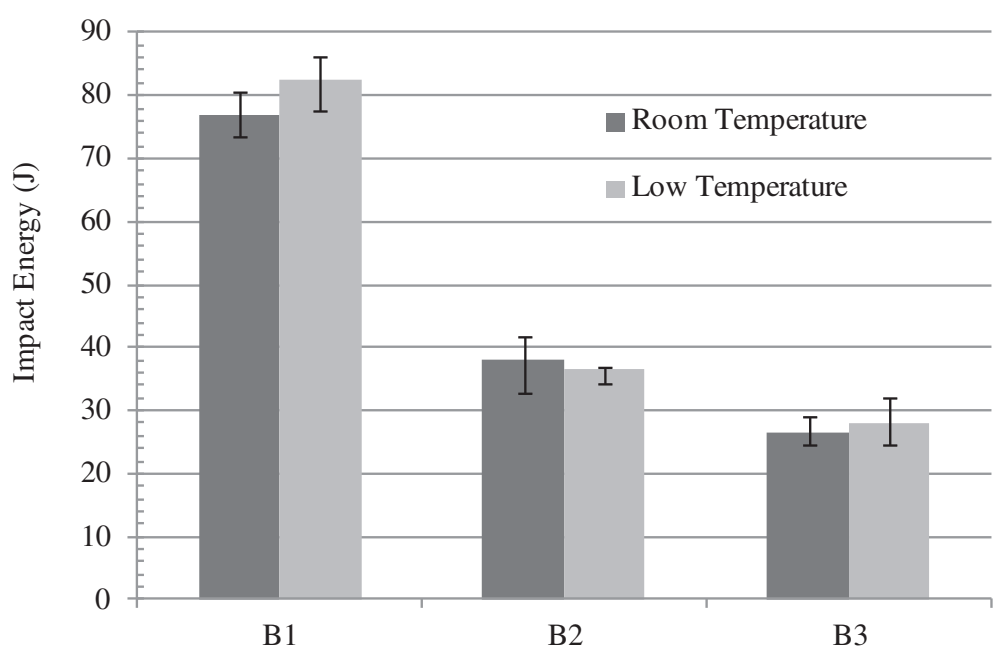

Figure 7 Impact toughness of brass. 


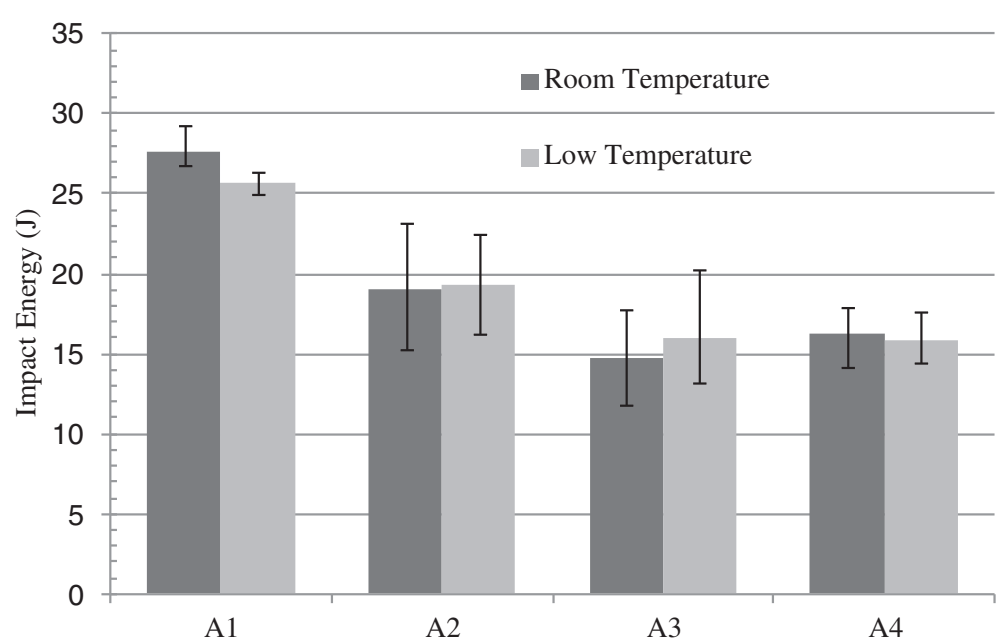

Figure 8 Impact toughness of aluminum.

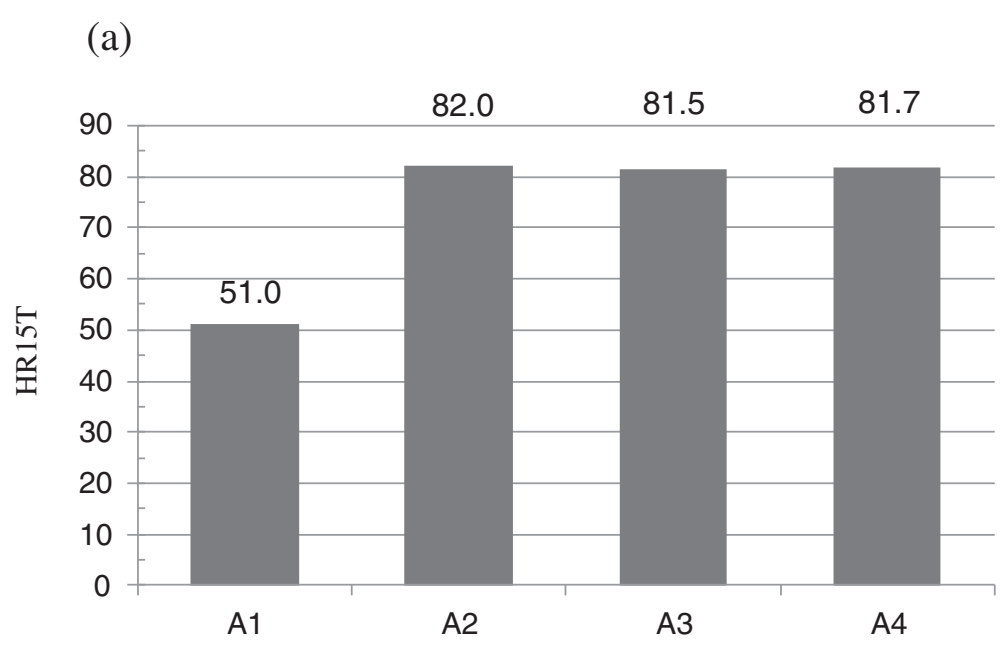

(b)

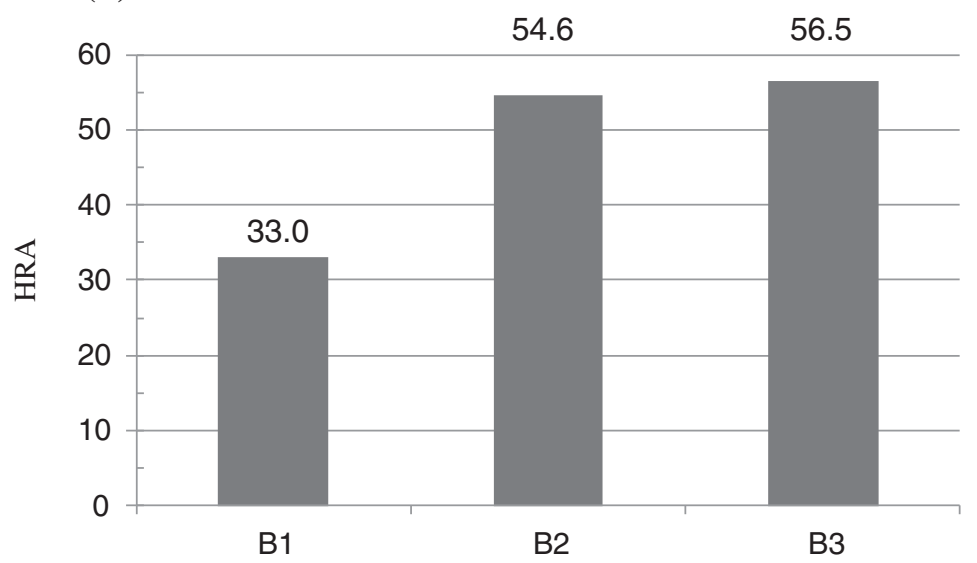

Figure 9 Hardness test results. Hardness test results of (a) aluminum and (b) brass. 
density tangles will subsequently provide localized concentrations of vacancies sufficient to form loops. This eventually results in the development of a higher number of very small subgrains (dislocation-free structures) with higher grain boundary misorientation angles in the ECAEprocessed materials with sufficient number of passes to induce severe plastic deformation (Rebhi et al. 2011).

To summarize, the hardness almost remained constant after two and four passes during ECAE processing as demonstrated for samples A2, A3, and A4 (for aluminum) and after two passes (B2, B3) for brass in Figure 9a,b. This is attributed mainly to the combination of deformation and UFG structures in aluminum and only deformation structure in the case of brass.

\section{Impact toughness}

Charpy impact tests were carried out at two different temperatures $\left(24.7^{\circ} \mathrm{C}\right.$ and $\left.-70^{\circ} \mathrm{C}\right)$. The impact toughness result of aluminum is depicted in Figure 8. The result shows that the averaged impact toughness of the asreceived specimen (A1) was about $25.8 \mathrm{~J}$ and was decreased after ECAE processing to about $16.3 \mathrm{~J}$ under both temperatures. Figures 10 and 11 are the SEM fractographs of specimen A1 (without ECAE processing) fractured at $24.7^{\circ} \mathrm{C}$, illustrating typical ductile-type fracture feature with large numbers of dimples. This condition was found to be identical with the specimen $\mathrm{A} 1$ tested at $-70^{\circ} \mathrm{C}$ as shown in Figure 12. These fractographs are clearly in agreement with the relatively higher values, in comparison to ECAE-processed aluminum specimens, of impact energy obtained from the Charpy test.

Figures 13 and 14 show the fracture surface characteristics of aluminum specimens $\mathrm{A} 2$ impacted at $24.7^{\circ} \mathrm{C}$ and $-70^{\circ} \mathrm{C}$, respectively. The fracture surface features were found to be almost identical with specimens A3 and A4. This conforms to the experimentally obtained values of similar impact

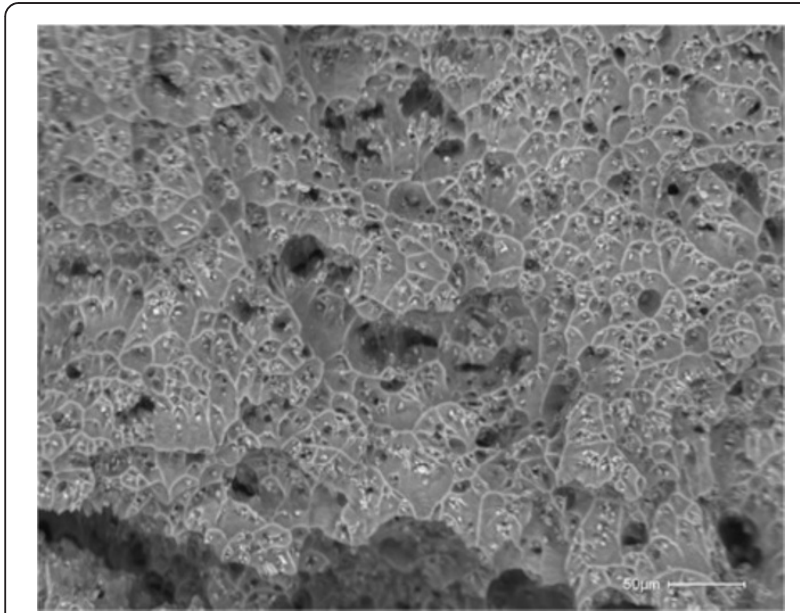

Figure 10 SEM fractograph of specimen A1 (room temperature) demonstrating large number of equiaxed dimpled structure.

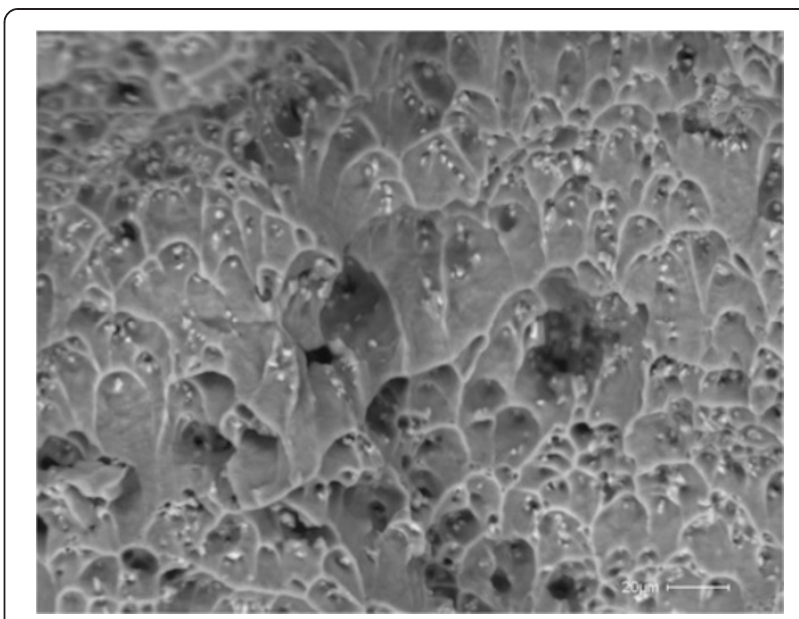

Figure 11 SEM fractograph of specimen A1 (room temperature) at a higher magnification showing voids and dimples.

energy for all three specimens. The decrease in the impact energy value between the as-received and the ECAE-processed specimens can be attributed to the presence of a few brittle-like regions (as demonstrated in Figure 14) due to deformation/dislocation structures during the extrusion process.

The impact toughness result of brass specimens is shown in Figure 7. It is clear that the impact energy of the as-received brass specimen B1, about $78.6 \mathrm{~J}$, was higher than that of the ECAE process specimens B2 and B3 (about $31.2 \mathrm{~J})$. The fracture surface characteristics of specimen $\mathrm{B} 1$ tested at $24.7^{\circ} \mathrm{C}$ and $-70^{\circ} \mathrm{C}$ are depicted in Figures 15 and 16, respectively. These demonstrate the process of void formation, coalescence, and growth of voids leading to ductile fracture. The ductile fracture surface features from both room and low temperaturetested samples conform to the experimental data that the impact energies of the ECAE samples are almost the same.

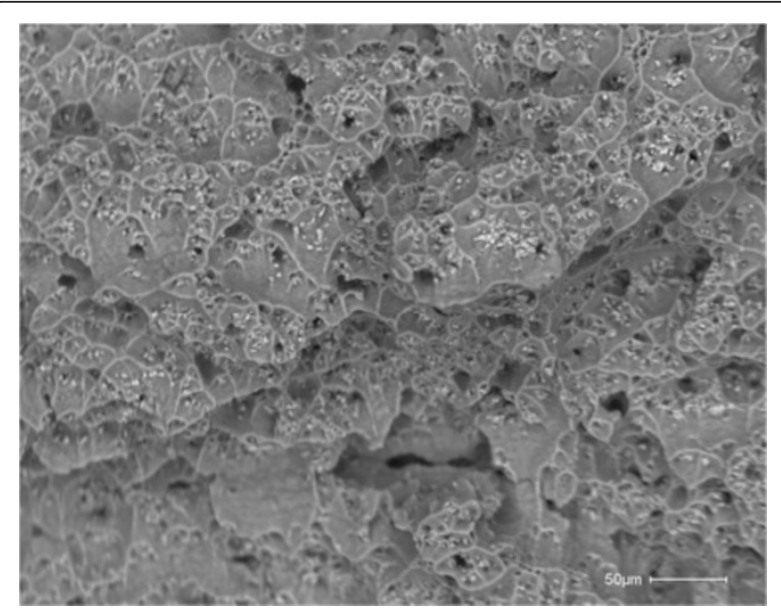

Figure 12 SEM fractograph of specimen A1 (low temperature) showing ductile fracture. 


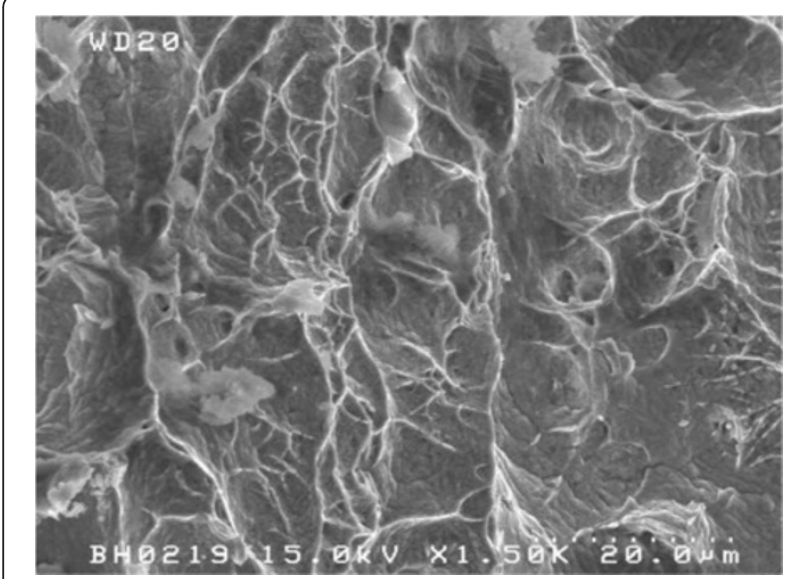

Figure 13 SEM fractograph features of specimen A2 (room temperature). The features are dominated by ductile fracture but with a few flat fracture surfaces.

Figures 17 and 18 are fractographs of ECAE-processed specimen $\mathrm{B} 2$ tested at $24.7^{\circ} \mathrm{C}$ and $-70^{\circ} \mathrm{C}$, respectively. The SEM fractographs reveal the presence of isolated brittle features in dominant ductile characteristics. Specimens B3 tested at room and low temperature showed fracture feature similar to that of B2. The fracture surface features in B2 and B3 are in agreement with the experimental impact energy data shown in Figure 7. While a decrease in hardness and an increase in ductility after ECAE for $\mathrm{Zn}-40 \mathrm{Al}$ alloy have been reported in Purcek et al. (2008), the hardness of aluminum and brass remained constant in the present investigation. Furthermore, the impact energy decreased for brass after two passes and remained almost constant for aluminum two or four passes after ECAE. These observations are mainly due to the combination of

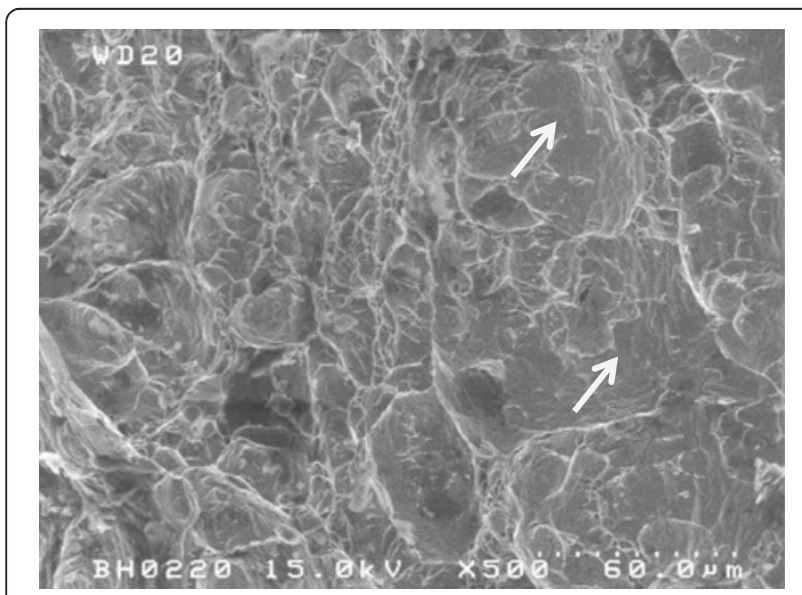

Figure 14 SEM fractograph features of specimen A2 (low temperature) with a few brittle-like regions. The features show predominantly ductile fracture with a few brittle-like regions (shown by arrows).

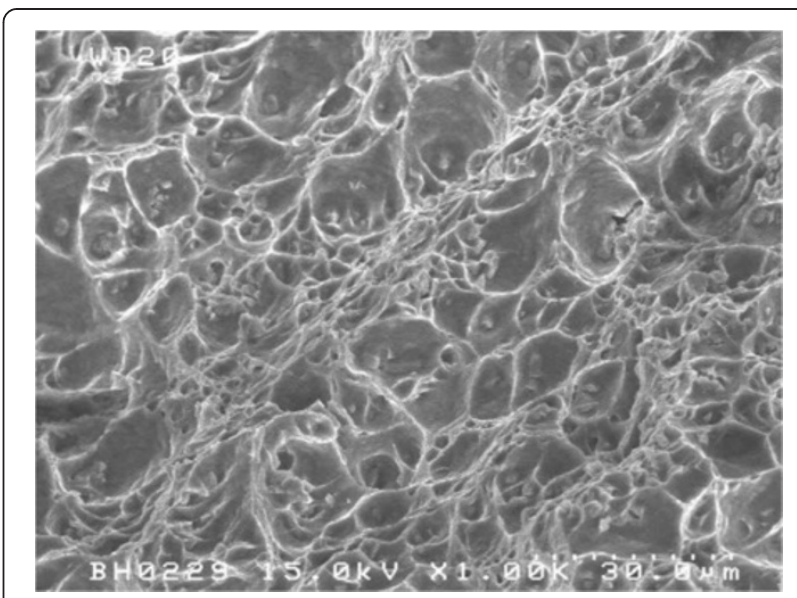

Figure 15 SEM fractograph features of specimen B1 (room temperature) with dominant ductile regions.

deformation and UFG structures observed in the present study as opposed to fully UFG structures after sufficient number of passes reported in Purcek et al. (2008).

From Figures 7 and 8, it can be observed that the impact energies of specimens tested at room temperatures were almost identical to the specimens tested at low temperatures. This is due to the well-known non-ductile-brittle transition temperature (DBTT) behavior of face-centered cubic (FCC) metals like aluminum and their alloys and the FCC crystal structure of alpha phase brass.

\section{Effect of notch surface on impact toughness}

One of the characteristics that can be overlooked is the effect of the V-notch surface on the impact toughness. For ECAE-processed specimens, it can be observed from Figure 8 that the impact energy of A2 $(19.1 \mathrm{~J})$ was higher than that of A3 (15.5 J) and A4 (16.0 J). Similarly from

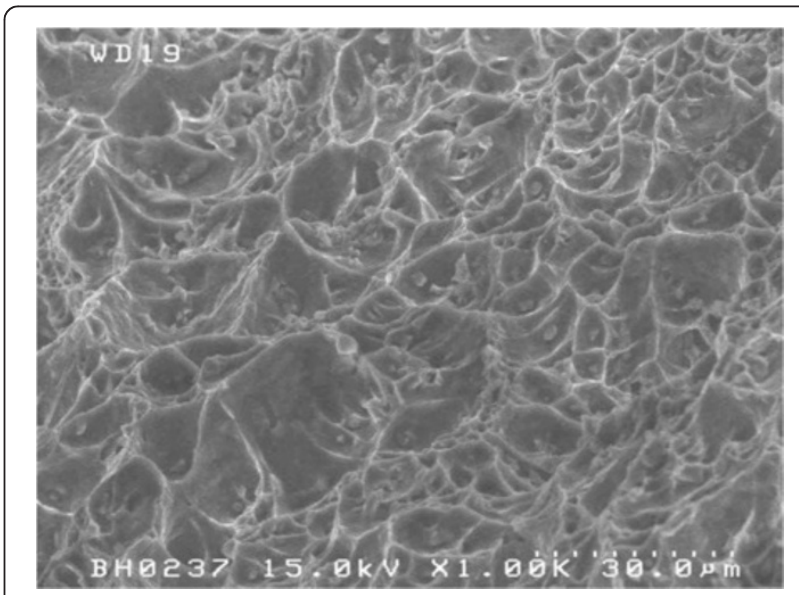

Figure 16 SEM fractograph features of specimen B1 (low temperature) with voids and dimples characteristic of ductile fracture. 


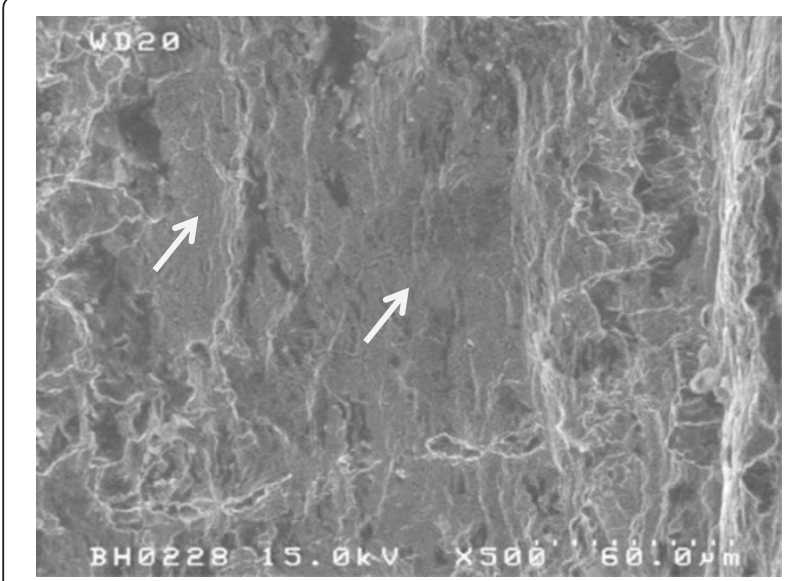

Figure 17 SEM fractograph of B2 (room temperature).

Fractograph shows a combination of ductile ridges and flat features of brittleness (shown by arrows).

Figure 7, the impact energy of B2 (37.0 J) was higher than that of B3 (27.2 J). Examining the ECAE processing routes and the distortion of the cubic element shown in Figure 19 (Furukawa et al. 1998), it was found that the notches on A2 and B2 (both route C, two passes) were machined on the undistorted $z$ plane. While the strain was restored for $\mathrm{A} 3$ and $\mathrm{B} 3$ (both route $\mathrm{C}$, two passes), the notched surfaces on $y$ plane were disturbed during ECAE processing. Also shown in Figure 19 (Furukawa et al. 1998), the notch of $A 4$ (route $B_{C}$, four passes) was created on the $z$ plane. Again, the notched surfaces were twice distorted during ECAE processing. The experimental data show that the impact toughness of specimens with the notch machined on the distorted and restored surface is lower than that of the specimens with the notch machined on the undistorted surface.

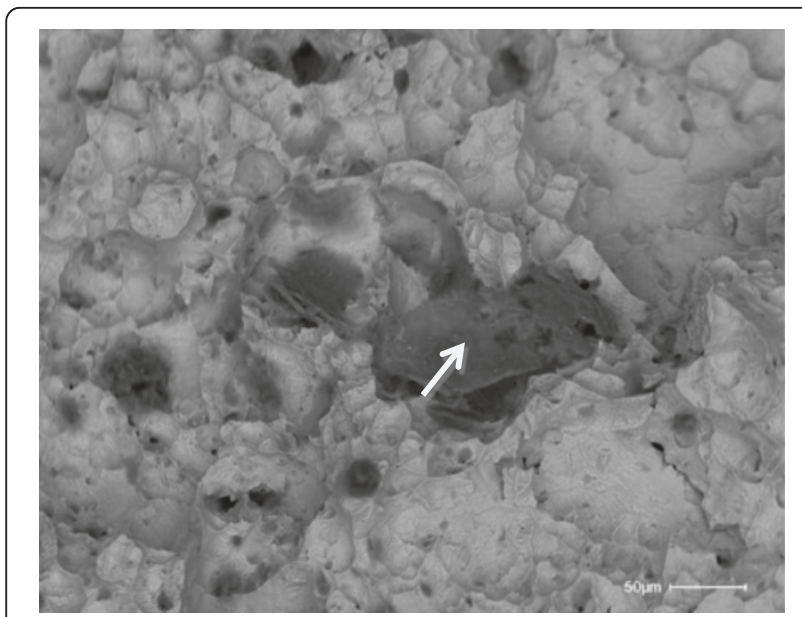

Figure 18 Fractograph of B2 (low temperature) revealing ductile features with isolated pockets of brittleness (shown by an arrow).

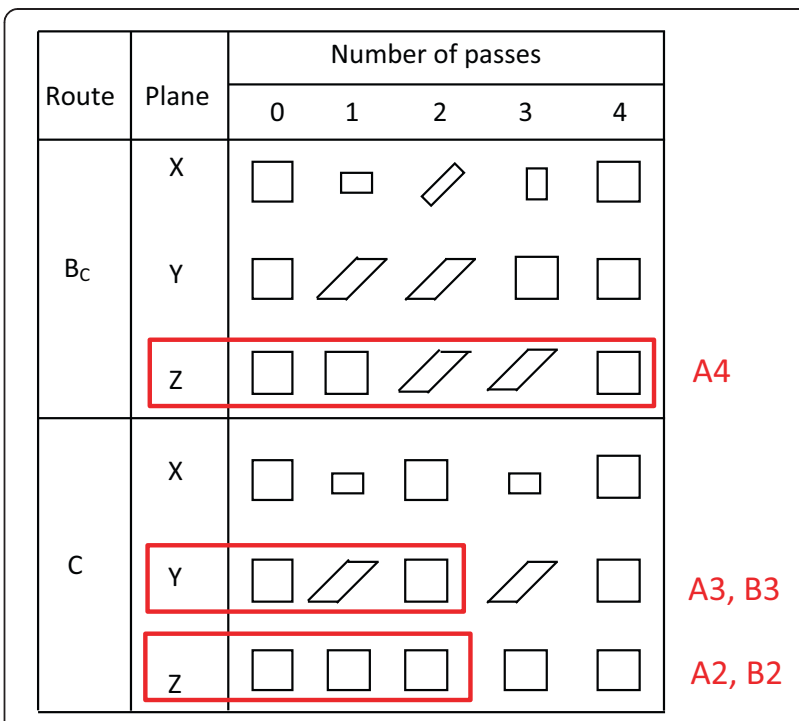

Figure 19 The distortion of the cubic elements for routes $B_{C}$ and C. Modified from Furukawa et al. (1998).

\section{Conclusions}

The influence of ECAE on the impact toughness of aluminum 1100 and brass C26000 at room and low temperatures has been investigated. The materials were processed using two ECAE routes, and the microstructure and the hardness of the materials were evaluated before and after ECAE. For Charpy impact testing, different specimens were prepared with notches, each machined on one of two different surfaces. These observed characteristics of the material properties can influence material and process selections in practical design applications. The results of the investigation are summarized as follows:

1. ECAE-processed aluminum demonstrated deformation/dislocation structures after two or three passes but showed a combination of dislocation and UFG structures as evident from the impact energy values.

2. In the case of brass, ECAE processing with two passes resulted in decrease in impact energy due to dominant deformation/dislocation structures as a result of increase in dislocation density/microstrain.

3. There is no appreciable difference in impact energy for materials tested in room temperature and in low temperature. The non-ductile brittle transition temperature behavior of FCC metals/alloys (both aluminum and brass in the present study) was observed.

4. The impact toughness can be affected by the surface where the notch was machined. It was found that the specimens with notch machined on an undistorted surface have higher impact energy than the specimens with notch on a distorted and restored surface. 


\section{Competing interests}

The authors declare that they have no competing interests.

\section{Authors' contributions}

JW planned the investigation, reviewed the results, and wrote the manuscript. $\mathrm{HZ}$ carried out the specimen preparation, conducted experiments, and prepared a rough draft of the manuscript. KVS conducted microstructure characterization and provided interpretation of the fractograph results. AHP supervised hardness and impact tests and analyzed test data. All authors read and approved the final manuscript.

\section{Author details}

'Department of Engineering Technology and Industrial Distribution, Texas A\&M University, College Station, Texas 77843-3367, USA. ${ }^{2}$ Department of Mechanical Engineering, Texas A\&M University, College Station, Texas 77843-3123, USA. ${ }^{3}$ Department of Metallurgical and Materials Engineering, Montana Tech of the University of Montana, Butte, MT 59701, USA.

Received: 28 August 2014 Accepted: 18 September 2014

Published online: 15 October 2014

\section{References}

Crone, WC, Yahia, AN, \& Perepezko, JH. (2001). Influence of grain refinement on superelasticity in NiTi. Proceedings of the SEM Annual Conference on Experimental Mechanics, Portland, OR, 510-513.

Firstov, S, Brodnikovsky, M, Danylenko, M, \& Podrezov, Y. (2003). Nanocrystalline structure formation under severe plastic deformation and its influence on mechanical properties. Reviews on Advanced Materials Science, 4, 155-162.

Furukawa, M, Iwahashi, Y, Horita, Z, Nemoto, M, \& Langdon, TG. (1998). The shearing characteristics associated with equal-channel angular pressing. Materials Science and Engineering A, 257, 328-332.

Georgy, RJ, Ruslan, VZ, Terry, LC, \& Zhu, YT. (2004). Continuous processing of ultrafine grained Al by ECAp-Conform. Materials Science and Engineering A, 382, 30-34.

Höppel, H, Kautz, M, Xu, C, Murashkin, M, Langdon, T, Valiev, R, \& Mughrabi, H. (2006). An overview: fatigue behaviour of ultrafine-grained metals and alloys. International Journal of Fatigue, 28, 1001-1010.

Iwahashi, Y, Horita, Z, Nemoto, M, \& Langdon, TG. (1997a). An investigation of microstructural evolution during equal-channel angular pressing. Acta Materialia, 45, 4733-4741.

Iwahashi, Y, Horita, Z, Nemoto, M, \& Langdon, TG. (1997b). An investigation of microstructural evolution during equal-channel angular pressing. Acta Materialia, 45, 4733-4741.

Langdon, TG, Furukawa, M, Nemoto, M, \& Horita, Z. (2000). Microstructural evolution during processing by severe plastic deformation. In TC Lowe \& RZ Valiev (Eds.), Investigation and Applications of Severe Plastic Deformation (pp. 149-154). Boston: Kluwer Academic Publishers.

$\mathrm{Li}, \mathrm{Z}$, \& Cheng, X. (2010). Improvement in wear resistance of TiNi alloy processed by equal channel angular extrusion and annealing treatment. Advanced Tribology, 1, 257-259.

Li, H, \& Ebrahimi, F. (2005). Ductile-to-brittle transition in nanocrystalline metals. Advanced Materials, 17, 1969-1972.

Li, S, Beyerlein, IJ, Necker, CT, Alexander, DJ, \& Bourke, M. (2004). Heterogeneity of deformation texture in equal channel angular extrusion of copper. Acta Materialia, $52,4859-4875$.

Purcek, G, Saray, O, Karaman, I, \& Kucukomeroglu, T. (2008). Effect of severe plastic deformation on tensile properties and impact toughness of two-phase $\mathrm{Zn}$-40al alloy. Materials Science and Engineering A, 490, 403-410.

Rebhi, A, Makhlouf, T, Champion, Y, Couzinie, JP, \& Nja, N. (2011). Microstructure investigation and thermal stability of $99.1 \%$ aluminum processed by equal channel angular extrusion. Journal of Materials Science, 46, 2185-2193.

Rebhi, MT, Njah, N, Champion, Y, \& Couzinié, JP. (2009). Characterization of aluminum processed by equal channel angular extrusion: Effect of pressing route. Materials Characterization, 60, 1489-1495.

Reihanian, M, Ebrahimi, R, Tsuji, N, \& Moshksar, M. (2008). Analysis of mechanical properties and deformation behavior of nanostructured commercially pure Al processed by equal channel angular pressing (ECAP). Materials Science and Engineering A, 473, 189-194.

Sivakumar, SM, \& Ortiz, M. (2004). Microstructure evolution in the equal channel angular extrusion process. Computer Methods in Applied Mechanics and Engineering, 193(48-51), 5177-5194
Stolyarov, W, Zhu, YT, Alexandrov, IV, Lowe, TC, \& Valiev, RZ. (2001). Influence of ECAP routes on the microstructure and properties of pure titanium. Materials Science and Engineering A, 299, 59-67.

Stolyarov, V, Valiev, R, \& Zhu, Y. (2006). Enhanced low-temperature impact toughness of nanostructured Ti. Applied Physics Letters, 88, 041905-041905-041903.

Valiev, RZ, \& Langdon, TG. (2006). Principles of equal-channel angular pressing as a processing tool for grain refinement. Progress in Materials Science, 51, 881-981.

Valiev, RZ, Islamgaliev, RK, \& Alexandrov, IV. (2000). Bulk nanostructured materials from severe plastic deformation. Progress in Materials Science, 45, 103-189.

Xiao, T, Miyamoto, H, \& Uenoya, T. (2012). Equal-channel angular pressing as a new processing to control the microstructure and texture of metallic sheets. Materials Sciences and Applications, 3, 600-605.

Xu, C, Száraz, Z, Trojanová, Z, Lukáč, P, \& Langdon, TG. (2008). Evaluating plastic anisotropy in two aluminum alloys processed by equal-channel angular pressing. Materials Science and Engineering A, 497, 206-211.

Zhu, YT, Huang, JY, Gubicza, J, Ungar, T, Ma, E, \& Valiev, RZ. (2003). Nanostructures in Ti processed by severe plastic deformation. Journal of Materials Research, 18, 1908-1917.

doi:10.1186/s40712-014-0019-2

Cite this article as: Wang et al:: Influence of equal-channel angular extrusion on impact toughness of aluminum and brass at room and low temperatures. International Journal of Mechanical and Materials Engineering 2014 9:19.

\section{Submit your manuscript to a SpringerOpen ${ }^{\odot}$ journal and benefit from:}

- Convenient online submission

- Rigorous peer review

- Immediate publication on acceptance

- Open access: articles freely available online

- High visibility within the field

- Retaining the copyright to your article

Submit your next manuscript at $>$ springeropen.com 